\title{
A New Direct Speed Estimation and Control of the Induction Machine Benchmark: Design and Experimental Validation
}

\author{
Ali Hmidet $\mathbb{D}^{1},{ }^{1}$ Rachid Dhifaoui $\mathbb{D}^{2},{ }^{2}$ and Othman Hasnaoui ${ }^{3}$ \\ ${ }^{1}$ Tunis El Manar University, Tunisia \\ ${ }^{2}$ Tunis Carthage University, Tunisia \\ ${ }^{3}$ University of Tunis, Tunisia \\ Correspondence should be addressed to Ali Hmidet; hmidetali@yahoo.fr
}

Received 24 July 2018; Accepted 9 September 2018; Published 8 October 2018

Guest Editor: Mihai Lungu

Copyright (C) 2018 Ali Hmidet et al. This is an open access article distributed under the Creative Commons Attribution License, which permits unrestricted use, distribution, and reproduction in any medium, provided the original work is properly cited.

\begin{abstract}
Speed sensorless control schemes have potential benefits for industrial applications because they contribute to reducing process cost and they avoid using fragile sensors as encoders or resolvers in hostile environment. In addition, simplicity, reliability, and fast response of control structures to signal commands are much-needed features. In this paper, a new Speed Sensorless Direct Control (SSDC) technique allowing the achievement of these objectives is proposed. This technique combines Field Oriented Control (FOC) and Direct Torque Control (DTC) properties in the same approach. The estimated speed is reached only according to the measured current and voltage of the stator. DTC is extended to speed sensorless direct control with any notable modification. The proposed scheme is implemented to the induction machine benchmark and evaluated in real time under various possible scenarios of use. Experimental results show that the proposed SSDC has interesting capabilities to conduct induction motor in real time operation with good accuracy.
\end{abstract}

\section{Introduction}

The variable speed control of electric drives has benefited in recent years from significant methodological and technological advances. In fact, advances in digital signal processors such as DSP and dSPACE kits and the development of power components today make it possible to implement very complex algorithms with a short computation time. Several control algorithms are developed, tested, and industrialized. Field oriented control (FOC) [1-3] and direct torque control (DTC) [4-8] are typical examples.

As is known, the available FOC structures require a speed sensor and the supply voltage is generated by an inverter governed by the Space Vector Pulse Width Modulation (SVPWM) strategy which is switching period generally in the order of 100 to 200 microseconds. By modulation principle, the switching times of the inverter IGBTs are variable in this range and can therefore reach very low values. The waveform of the current is then sufficiently smooth. The torque and speed rising times in the closed loop operating points are about the rotor time constant [9]. FOC has the disadvantage that requiring the use of a speed sensor or position which imposes an additional cost and increases the complexity of the drive system.

Conventionally, DTC structures are speed sensorless controls. In contrast to the FOC method, the DTC technique eliminates PI controllers, transform matrices, current regulators, and PWM stage. Inverter IGBTs are in fact controlled with constant switching time that lies in general in the range of 25 to 50 microseconds. Torque and stator flux magnitude are regulated by adequately selecting a voltage vector among those available on the inverter $[6,8]$. The practical implementation is therefore more economical and simpler and requires a shorter calculation time. The cancellation of a speed sensor is certainly a significant advantage. The speed response of the DTC is slow, unlike the torque response. Furthermore, torque response is very fast. Such a property is in demand in many industrial applications such as electric traction and tools-machine. Important current and torque ripples occur if the selected voltage vector isn't the best one. In practical point 
of view, the DTC scheme can fall down if torque and flux hysteresis bands do not adequately take into account values of switching period and inverter dc voltage [10].

FOC and DTC are well studied and compared in various publications $[9,11-13]$. Specific futures, advantages, and drawbacks are outlined. However, the possibility of connection of FOC and DTC in the same purpose is not sufficiently investigated. In fact, a Like-FOC or Like-DTC or FOC-DTC approach can be of great interest. The key point of this paper deals with this aspect. It consists of combining FOC and DTC potentialities to study an important practical problem dealing with speed estimation and control of induction machines benchmark. It is based on the extension of the good torque regulation in the DTC structure into a speed regulation while benefiting of its advantages. Speed sensing based on encoders or resolvers is expensive on one hand and is vulnerable to hostile environment on the other hand. Closed loop control based on numerical estimation of machine rpm is therefore highly demanded [14-20].

The proposed algorithm for estimating and controlling the speed of the induction machine benchmark is experimentally verified in real time running on Dspace DS1104. Practical results prove that the DTC scheme can be extended to realize a reliable and efficient speed sensorless approach. This approach uses some expressions and properties of FOC. The developed method is here labelled Speed Sensorless Direct Control (SSDC).

The paper is organized as follows. Section 2 presents the theoretical background of induction machine benchmark and some properties emerging from selecting adequate reference frame. Section 3 develops theoretical and practical features of standard DTC technique. Section 4 describes the speed estimation and control approach. The idea is focused on how to use standard Takahashi switching table to control induction machine speed. Section 5 deals with practical results and discussion.

\section{Basics of Induction Machine Benchmark}

The dynamic model of induction machine can be formulated according to $\mathrm{d}$-q-axis components in various reference frames. Let us first consider Concordia's stationary reference frame. The usual following set of equations is used [21]:

$$
\begin{aligned}
& \bar{e}_{s}=\frac{d \bar{\varphi}_{s}}{d t}=\bar{v}_{s}-R_{s} \bar{i}_{s} \\
& \bar{e}_{r}=\frac{d \bar{\varphi}_{r}}{d t}=j \omega \bar{\varphi}_{r}-R_{r} \bar{i}_{r} \\
& \bar{\varphi}_{s}=\ell_{s} \bar{i}_{s}+m \bar{\varphi}_{r}
\end{aligned}
$$

where $\bar{v}_{s}$ and $\bar{i}_{s}$ correspond to stator voltage and current vectors, $\bar{e}_{s}$ and $\bar{e}_{r}$ are stator and rotor electromotive forces (back emfs), and $\bar{\varphi}_{s}$ and $\bar{\varphi}_{r}$ are stator and rotor flux vectors. Variable $\omega$ holds for electrical rotor speed. Parameters $R_{s}, R_{r}$, $\ell_{s}$, and $m$ are stator and rotor resistance, leakage inductance, and the ratio between mutual inductance $M$ and rotor inductance $L_{r}$, respectively. This model is established under the assumption of no eddy currents, no saturation of the magnetic circuit, and the additional assumption of sinusoidal distribution of the stator and rotor windings.

In normal steady state, stator and rotor electrical variables have sinusoidal wave forms with the same frequency and different magnitudes that depend on the considered operating point. These quantities vary in transient regime according to the adopted control. Various expressions can be used to calculate electromagnetic torque. The most used relation is the following where $p$ holds for the number of pairs of poles and $\Im_{m}(\cdot)$ designates the imaginary component of the treated complex quantity. This relation is common for steady state and transient regimes $[3,6]$.

$$
T_{e}=-p \mathfrak{\Im}_{m}\left(\bar{\varphi}_{s} \bar{i}_{s}^{*}\right)=p\left(\varphi_{d s} i_{q s}-\varphi_{q s} i_{d s}\right)
$$

In what follows, it will be very helpful to express stator and rotor flux vectors as functions of their magnitudes and angles:

$$
\begin{aligned}
& \bar{\varphi}_{s}=\Phi_{s} e^{j \theta_{s}} \\
& \bar{\varphi}_{r}=\Phi_{r} e^{j \theta_{r}}
\end{aligned}
$$

Let us now consider a reference frame rotating with an angle $\theta_{p}$ (or frequency $\omega_{p}$ ) with respect to Concordia's stationary reference frame. The famous Park's d-q axes system is considered. Voltage equations (1) and (2) of Concordia's model become as follows in this new rotating reference frame; the capital letters is used to distinguish between these two systems [22]:

$$
\begin{aligned}
& \bar{E}_{s}=j \omega_{p} \bar{\Phi}_{s}+\frac{d \bar{\Phi}_{s}}{d t}=\bar{V}_{s}-R_{s} \bar{I}_{s} \\
& \bar{E}_{r}=j \omega_{p} \bar{\Phi}_{r}+\frac{d \bar{\Phi}_{r}}{d t}=j \omega \bar{\Phi}_{r}-R_{r} \bar{I}_{r}
\end{aligned}
$$

Transition from Concordia's variables to Park's ones is realized by the rotation operator $e^{-j \theta_{p}}$. For example, stator current becomes $[7,20,22]$

$$
\bar{I}_{s}=\bar{i}_{s} e^{-j \theta_{p}}
$$

According to a specific topic, a suitable Park reference frame is selected. In practical point of view, there are two very interesting cases. The first one concerns a rotating reference frame hose $d$-axis is aligned to stator flux vector $\bar{\varphi}_{s}$. This case leads to some interesting properties used in control strategies considering machine stator control as fundamental target. The second case deals with a rotating reference synchronized with rotor flux vector $\bar{\varphi}_{r}$. The attention is then focused on rotor variables control as flux magnitude and slip frequency control schemes.

In the case of a stator flux reference frame, angle $\theta_{p}$ is equal to $\theta_{s}$, which means $\Phi_{d s}=\Phi_{s}$ and $\Phi_{q s}=0$. Thus, decomposing (6) into d-q components leads to

$$
\begin{aligned}
& \frac{d \Phi_{s}}{d t}=E_{d s}=V_{d s}-R_{s} I_{d s} \\
& \frac{d \theta_{s}}{d t}=\omega_{s}=\frac{E_{q s}}{\Phi_{s}}=\frac{V_{q s}-R_{s} I_{q s}}{\Phi_{s}}
\end{aligned}
$$




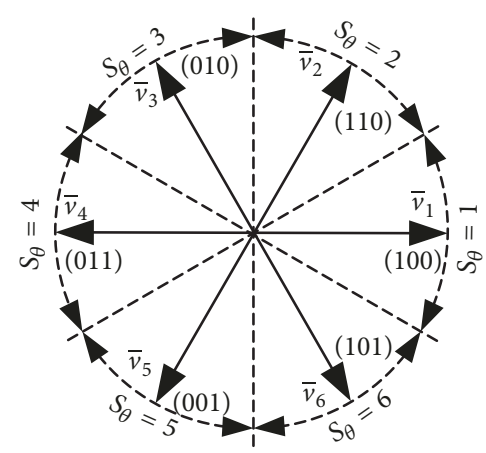

FIGURE 1: Inverter voltage vectors in Concordia’s reference frame.

The most important conclusion that can be derived from this model is the fact that stator flux magnitude $\Phi_{s}$ is controllable from direct back emf component $E_{d s}$ while control of stator flux pulsation $\omega_{s}$ can be achieved by quadrature back emf component $E_{q s}$ [23-25]. This implies that stator control is by principle a voltage control.

For a rotor flux reference frame, angle $\theta_{p}$ is equal to $\theta_{r}$, which means $\Phi_{d r}=\Phi_{r}$ and $\Phi_{q r}=0$. Therefore, decomposing (7) into $\mathrm{d}$ and q components leads to the following model, where $\tau_{r}$ holds for rotor time constant $\left(\tau_{r}=L_{r} / R_{r}\right)$ :

$$
\begin{gathered}
\frac{d \Phi_{r}}{d t}=\frac{M I_{d s}-\Phi_{r}}{\tau_{r}} \\
\frac{d\left(\theta_{r}-\theta\right)}{d t}=\omega_{s l}=\omega_{r}-\omega=\frac{M I_{q s}}{\tau_{r} \Phi_{r}}
\end{gathered}
$$

This model implies that rotor flux magnitude $\Phi_{r}$ is controllable from direct stator current component $I_{d s}$ while control of electrical slip frequency $\omega_{s l}$ can be achieved by controlling quadrature current component $I_{q s}$. This is the most important theoretical result of FOC schemes. Rotorbased control is by principle a current control.

\section{Fundamentals of the DTC Scheme}

In variable $\mathrm{AC}$ drives, a three-phase voltage source inverter feeds the induction machine. For a lossless-admitted inverter, the output voltage is strictly defined by the dc bus voltage $V_{d c}$ of the inverter and the logical state of the three highest IGBT's signals $\left(c_{1}, c_{2}, c_{3}\right)$ of its configuration. There are only eight possible different logical combinations of $\left(c_{1}, c_{2}, c_{3}\right)$ leading to six active voltage vectors and two zero voltage vectors. It is well known that, for a specified switching combination of $\left(c_{1}, c_{2}, c_{3}\right)$, the space vector of the inverter output voltage $\bar{v}_{k}$ can be expressed as follows where $k$ an integer is indicating the switching combinations $[22,23]$ :

$$
\begin{aligned}
& \bar{v}_{k}=\sqrt{\frac{2}{3}} V_{d c} e^{j(k-1)(\pi / 3)} \quad k=1,2, \ldots, 6 \\
& \bar{v}_{k}=0 \quad k=0,7
\end{aligned}
$$

Figure 1 summarizes this model by indicating on each vector the associated combination of signal commands $c_{1}, c_{2}$, and $c_{3}$. Also, it is useful to identify active voltage vectors by six centered sector $S_{\theta}=1, \ldots, 6$.

Any proposed control scheme is developed to find out different solutions with two major objectives, accurate and quick control of the motor regime on one hand and reduction of the complexity and the cost of the algorithm on the other hand. Direct torque control (DTC) scheme developed and presented by I. Takahashi [3] is straight forward in these objectives. DTC is in fact characterized by the absence of PI regulators, absence of coordinate transformations, absence of current regulators, and absence of PWM signals generators.

First, let us note that induction machine benchmark achieves the demanded load if adequate stator flux magnitude and frequency are realised. Stator flux vector is therefore a key variable in any emphasised control. It is observed by Takahashi that stator flux control can be achieved in a simple way if the motor is fed by a three phase inverter. According to (1), stator flux vector can be generated by simple integration as follows:

$$
\bar{\varphi}_{s}=\int \bar{e}_{s} d t
$$

Furthermore, if the inverter command is maintained during a time interval $T_{s}$, it is possible to directly calculate stator flux vector variation according to (15) because voltage vector is constant.

$$
\bar{\varphi}_{s}\left(t_{o}+T_{s}\right)=\bar{\varphi}_{s}\left(t_{o}\right)+T_{s} \bar{v}_{s}
$$

According to this relation, selecting a null $\bar{v}_{s}$ vector stops the stator flux vector in the d-q plane. Instead, the selection of an active $\bar{v}_{s}$ vector moves the stator flux vector along the direction of the applied stator voltage. Furthermore, vector flux deviation is known and is strictly defined by the switching period $T_{s}$ and the inverter dc link voltage $V_{d c}$ as

$$
\left\|\bar{\varphi}_{s}\left(t_{o}+T_{s}\right)-\bar{\varphi}_{s}\left(t_{o}\right)\right\|=\sqrt{\frac{2}{3}} T_{s} V_{d c}
$$

Consequently, with appropriate sequence of the inverter command, the stator flux vector can be driven along any trajectory with a predefined average speed. The most appropriate flux trajectory for electrical machines control is naturally the circular path in the $\mathrm{d}-\mathrm{q}$ plane. A very simple way to obtain this trajectory is to use a hysteresis comparator to control the flux vector. In order to maintain the flux within the hysteresis band, the motor should be currently fed by a suitable voltage vector with a constant switching period $T_{s}$. The direct component $v_{d s}$ acts on the flux magnitude while the tangential component $v_{q s}$ determines the vector rotation. This is compatible with (9) and (10) that give the following under the assumption of constant current over the switching period:

$$
\begin{gathered}
\Delta \Phi_{s}=\frac{d \Phi_{s}}{d t} T_{s}=\left(V_{d s}-R_{s} I_{d s}\right) T_{s} \\
\Delta \theta_{s}=\frac{d \theta_{s}}{d t} T_{s}=\frac{\left(V_{q s}-R_{s} I_{q s}\right) T_{s}}{\Phi_{s}}
\end{gathered}
$$




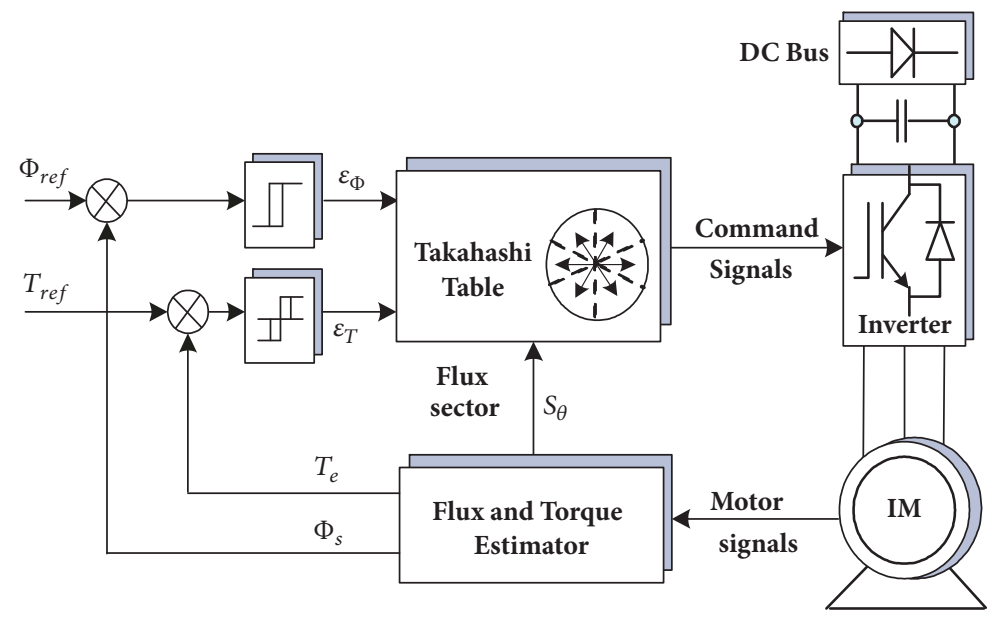

FIGURE 2: General structure of a DTC scheme.

On the other hand, accelerating or decelerating stator flux rotation is naturally linked to electromagnetic torque variation. Therefore, variation of angle $\theta_{s}$ can be used to control torque. Theoretically speaking, one can establish the sensitivity coefficient of $T_{e}$ with respect to flux magnitude and angle [23-26]. Let us consider (19) to describe electromagnetic torque. This equation is deduced from (3), (4), and (5):

$$
T_{e}=\frac{p m \Phi_{s} \Phi_{r}}{\ell_{s}} \sin \left(\theta_{s}-\theta_{r}\right)
$$

Stator and rotor machine circuits have different time responses. It is well known that stator variables vary more rapidly as compared to rotor ones. Stator quantities define a fast mode while rotor quantities correspond to a slow mode. Therefore, if flux magnitude is first controlled, a negative deviation of $T_{e}$ can be achieved by decelerating $\theta_{s}$ while a positive deviation is obtained by accelerating $\theta_{s}$. This means that by the same voltage vector $\bar{v}_{s}$ one can control simultaneously electromagnetic torque and stator flux magnitude. As done for stator flux magnitude control, a simple hysteresis control can be used to command torque. During this kind of control, torque value remains in the considered hysteresis band if the voltage vector is adequately selected.

Note finally that the effect of a particular voltage vector on torque and flux magnitude depends on the position $\theta_{s}$ of $\bar{\varphi}_{s}$ in the d-q plane. The choice of hysteresis bands and voltage vector affect the performance of the drive. This problem is largely studied in the related literature and people experience is today summarized by the well-known Takahashi Switching Table principle. Various switching solutions are established to control the torque according to whether the stator flux has to be increased or decreased. These solutions have similar capabilities in terms of torque ripples. In all cases, Figure 2 shows DTC structure.

The widely used DTC algorithm is built with six centered sectors for $\theta_{s}$, one level hysteresis comparator for stator flux
TABLE 1: Flux and torque errors codification.

\begin{tabular}{lc}
\hline Flux and torque errors & Hysteresis index \\
\hline$\left|\Delta \Phi_{s}\right|>\varepsilon_{\Phi}$ & $k_{\Phi}=1$ \\
$\left|\Delta \Phi_{s}\right| \leq \varepsilon_{\Phi}$ & $k_{\Phi}=2$ \\
$\Delta T_{e}>\varepsilon_{T}$ & $k_{T}=1$ \\
$\left|\Delta T_{e}\right| \leq \varepsilon_{T}$ & $k_{T}=2$ \\
$\Delta T_{e}<-\varepsilon_{T}$ & $k_{T}=3$ \\
\hline
\end{tabular}

TABLE 2: A Takahashi switching table.

\begin{tabular}{lcccccc}
\hline$k_{\Phi}$ & 1 & 1 & 1 & 2 & 2 & 2 \\
\hline$k_{T}$ & 1 & 2 & 3 & 1 & 2 & 3 \\
\hline$S_{\theta}=1$ & $\bar{v}_{2}$ & $\bar{v}_{0}$ & $\bar{v}_{6}$ & $\bar{v}_{3}$ & $\bar{v}_{7}$ & $\bar{v}_{5}$ \\
\hline$S_{\theta}=2$ & $\bar{v}_{3}$ & $\bar{v}_{7}$ & $\bar{v}_{1}$ & $\bar{v}_{4}$ & $\bar{v}_{0}$ & $\bar{v}_{6}$ \\
\hline$S_{\theta}=3$ & $\bar{v}_{4}$ & $\bar{v}_{0}$ & $\bar{v}_{2}$ & $\bar{v}_{5}$ & $\bar{v}_{7}$ & $\bar{v}_{1}$ \\
\hline$S_{\theta}=4$ & $\bar{v}_{5}$ & $\bar{v}_{7}$ & $\bar{v}_{3}$ & $\bar{v}_{6}$ & $\bar{v}_{0}$ & $\bar{v}_{2}$ \\
\hline$S_{\theta}=5$ & $\bar{v}_{6}$ & $\bar{v}_{0}$ & $\bar{v}_{4}$ & $\bar{v}_{1}$ & $\bar{v}_{7}$ & $\bar{v}_{3}$ \\
\hline$S_{\theta}=6$ & $\bar{v}_{1}$ & $\bar{v}_{7}$ & $\bar{v}_{5}$ & $\bar{v}_{2}$ & $\bar{v}_{0}$ & $\bar{v}_{4}$ \\
\hline
\end{tabular}

magnitude control and a two levels hysteresis comparator for torque control. Let $\Delta T_{e}$ and $\Delta \Phi_{s}$ be the torque and flux errors with respect to their reference values.

$$
\begin{gathered}
\Delta T_{e}=T_{r e f}-T_{e} \\
\Delta \Phi_{s}=\Phi_{r e f}-\Phi_{s}
\end{gathered}
$$

Let also $\varepsilon_{T}$ and $\varepsilon_{\Phi}$ be the considered values of associated hysteresis bands. Table 1 reports the different possible situations and associates two indexes $k_{T}$ and $k_{\Phi}$ for codification purpose.

In the sense of this codification, Table 2 defines Takahashi Switching Table where states for the sector location of stator flux vector. 
TABLE 3: Flux and speed errors codification for two cases of loads.

\begin{tabular}{lcc}
\hline Flux and speed errors & Hysteresis index for Load 1 & Hysteresis index for load 2 \\
\hline$\left|\Delta \Phi_{s}\right| \leq \varepsilon_{\Phi}$ & $k_{\Phi}=1$ & $k_{\Phi}=1$ \\
$\left|\Delta \Phi_{s}\right|>\varepsilon_{\Phi}$ & $k_{\Phi}=2$ & $k_{\Phi}=2$ \\
$\Delta \omega>\varepsilon_{\omega}$ & $k_{\omega}=1$ & $k_{\omega}=3$ \\
$|\Delta \omega| \leq \varepsilon_{\omega}$ & $k_{\omega}=2$ & $k_{\omega}=2$ \\
$\Delta \omega<-\varepsilon_{\omega}$ & $k_{\omega}=3$ & $k_{\omega}=1$ \\
\hline
\end{tabular}

\section{Extension of the DTC Scheme to Direct Speed Estimation and Control}

It has seen in the previous section that electromagnetic torque varies in the same sense as stator flux vector angle $\theta_{s}$. Therefore, if the load torque-speed curve of an industrial process has positive slope over the operating area, machine speed should also vary in the same sense of $\theta_{s}$. Processes having linear, parabolic, or in general positive polynomial torque-speed curves correspond to this situation. A typical and didactic example is the case of an induction machine loaded by a dc generator. On the contrary, if the load mechanical torque-speed curve has a negative slope, such as machine tools, the speed should be adjusted is the reverse sense of flux angle $\theta_{s}$. Let these two cases of loads be noted "Loadl" and "Load2," respectively.

Therefore, one can use the same DTC algorithm previously defined to control the motor speed with minor modification. This modification should not affect the switching table and should only affect its codification. First, it is necessary to change the input corresponding to electromagnetic torque $T_{e}$ by an input associated to machine speed $\omega$. Hysteresis band $\varepsilon_{T}$ corresponding to $T_{e}$ should be consequently changed by an adequate band $\varepsilon_{\omega}$. Then, if the used load is "Loadl" there is no additional modification to do. In contrary, if one deals with "Load2," he permutes indexes $k_{T}=1$ and $k_{T}=3$. Table 1 is then transformed into Table 3 where

$$
\Delta \omega=\omega_{r e f}-\omega
$$

Now, the problem is how to estimate motor electrical rotor speed $\omega$. This can be done according to SFOC and RFOC properties. This means that the potentialities of these two control options must be combined with DTC principle. For this purpose, assume that stator flux vector $\bar{\varphi}_{s}$ is obtained by integration of stator back emf $\bar{e}_{s}$ as indicated by (14) and rotor flux vector $\bar{\varphi}_{r}$ is deduce from (3); stator current being measured. Stator flux magnitude $\Phi_{s}$ and angle $\theta_{s}$ and rotor flux magnitude $\Phi_{r}$ and angle $\theta_{r}$ are thus available. Also, quadrature component $E_{q s}$ of $\bar{e}_{s}$ with respect to vector $\bar{\varphi}_{s}$ and quadrature current component $I_{q s}$ with respect to vector $\bar{\varphi}_{r}$ become available by setting:

$$
\begin{gathered}
E_{q s}=\Im_{m}\left(\bar{e}_{s} e^{-j \theta_{s}}\right) \\
I_{q s}=\Im_{m}\left(\bar{i}_{s} e^{-j \theta_{r}}\right)
\end{gathered}
$$

As outlined in Section 2, (10) gives an estimate of instantaneous stator flux pulsation $\omega_{s}$. On the other hand, electrical

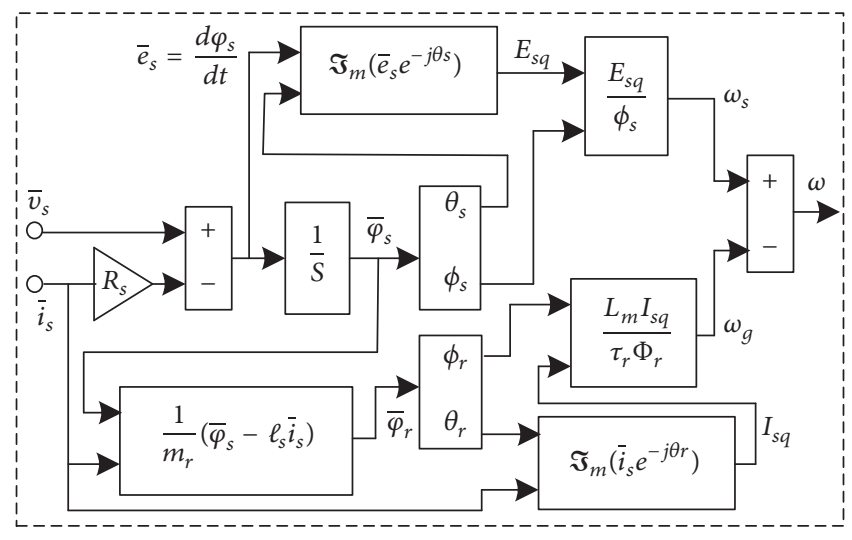

FIGURE 3: Schematic diagram of rotorique speed estimation.

rotor-slip pulsation $\omega_{s l}$ can be derived from (12) that needs rotor flux magnitude $\Phi_{r}$ and quadrature current component $I_{q s}$ with respect to vector $\bar{\varphi}_{r}$. By considering the assumption that in steady state, fluxes vectors $\bar{\varphi}_{s}$ and $\bar{\varphi}_{r}$ have the same pulsation [27] and one can estimate electrical machine speed $\omega$ by

$$
\omega \approx \frac{E_{q s f}}{\Phi_{s}}-\frac{M I_{q s f}}{\tau_{r} \Phi_{r}}
$$

In the previous equation, $E_{q s f}$ and $I_{q s f}$ are filtered values of $E_{q s}$ and $I_{q s}$, respectively. Note here that there is no need to filter flux magnitudes $\Phi_{s}$ and $\Phi_{r}$ because they are sufficiently smooth. Furthermore, simple first order transfer functions with constant time about $5 \mathrm{~ms}$ are sufficient to have acceptable smooth signal. The hypothesis considering equality of $\omega_{s}$ and $\omega_{r}$ can be a subject to discuss. However, keeping in mind that speed command is executed with some delay with respect to flux command; this hypothesis will be verified in practical implementation.

It is also important to note that error between actual rotor speed sensed for example by a tachometer or encoder and estimated speed defined by (24) can only be important during the first instant of the motor start-up operation. This has no effect on the final accuracy of the proposed estimation procedure because the estimated speed value is dominated by the first right term of (24). In other words, estimated stator flux pulsation that governs speed is the direct result of dc link inverter voltage and the controlled stator flux magnitude. Figure 3 illustrates the block diagram of the proposed algorithm to estimate motor electrical rotor speed. 


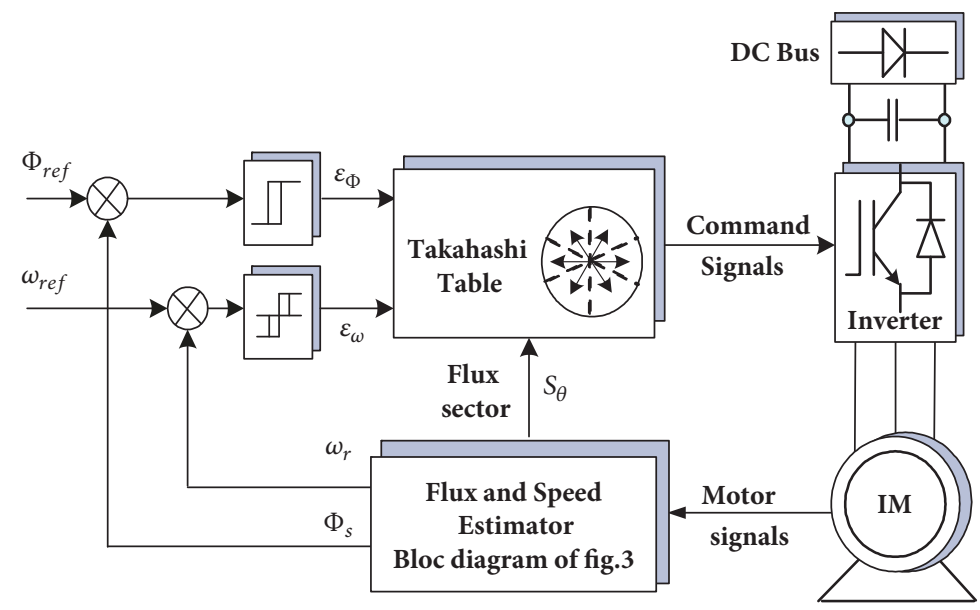

FIGURE 4: General Structure of the proposed SSDC control.

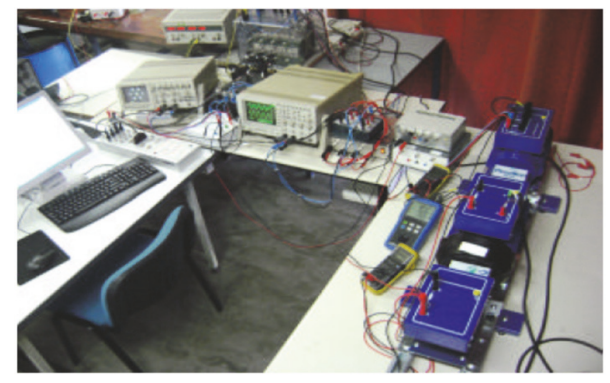

Figure 5: Photo of one side of the experimental setup.

As a result of this development, Figure 2 is transformed into Figure 4

We note here that this structure can be used as direct voltage control structure by replacing the input electrical rotor speed $\omega_{r}$ by stator electrical speed $\omega_{s}$.

\section{Real Time Experimental Validation}

5.1. Brief Description of the Benchmark. The previous developed algorithm is implemented and tested in an experimental environment. Photo of Figure 5 presents actual views of the experimental setup. The benchmark consists of

(i) a dSpace DS1104 controller board with TMS320F240 slave processor and ADC interface board CP1104. The DS1104 board is installed in Intel(R) Pentium(R) D CPU 3.4 GHz PC for software development and results visualization,

(ii) a four poles induction motor loaded with a dc generator. Actual rotor speed is sensed from a tachometer coupled to machine shaft. Motor parameters and rated values are given below:

$\mathrm{Rs}=7.5 \Omega, \mathrm{Rr}=6.5 \Omega, \mathrm{Ls}=\mathrm{Lr}=0.354 \mathrm{H}, \mathrm{M}=0.34 \mathrm{H}$, $\mathrm{p}=2, \mathrm{~F}=50 \mathrm{~Hz}, \mathrm{Wn}=293.22 \mathrm{rad} / \mathrm{s}, \mathrm{Pn}=1 \mathrm{KW}$, $\cos \varphi_{\mathrm{n}}=0.78,220 \mathrm{~V} / 380 \mathrm{~V}$. (iii) a three-phase VSI whose dc bus voltage is generated by a rectifier connected to $400 \mathrm{~V} 50 \mathrm{~Hz}$ AC electrical sources,

(iv) a four channels $150 \mathrm{MHz}$ digital oscilloscope and two channels $20 \mathrm{MHz}$ analog oscilloscope support the experiment for online recording and visualization,

(v) current and voltage sensors LEM-based and calibrated so that the analogue obtained signals should remain in the range 0 to $\pm 10 \mathrm{~V}$ required by $\mathrm{d}$ Space converters.

The benchmark includes many other devices such as standard measurement equipment, analogue signal filters, analogues circuits defining $\mathrm{d}$ - $\mathrm{q}$ voltage, and currents components.

5.2. Results and Comments. To evaluate the performance of the proposed SSDC algorithm, it was implemented in Simulink dSPACE DS1104 environment. The implemented structure is composed by four blocs: voltage and current acquisition, flux and speed estimation, switching table and command signals. A constant switching period $T_{s}=50 \mu \mathrm{s}$ is considered. The three-phase VSI is supplied by a dc voltage $V_{d c}=500 \mathrm{~V}$ and motor windings are star connected. Induction motor is loaded by a dc generator giving an open circuit voltage about $150 \mathrm{~V}$ at nominal speed. This generator supplies an adjustable resistance. All results are realized in real time closed loop control.

Case 1 (no load test). This case verifies the algorithm for a motor start-up scenario under no load condition. Stator flux and electrical rotor speed commands are set to $\Phi_{r e f}=1 \mathrm{~Wb}$ and $\omega_{\text {ref }}=293 \mathrm{rad} / \mathrm{s}$, respectively. Associated hysteresis bands are taken equal to $5 \%$ of the command values; $\varepsilon_{T}=$ $0.05 \mathrm{~Wb}$ and $\varepsilon_{\omega}=14.7 \mathrm{rad} / \mathrm{s}$. Stator flux vector pulsation $\omega_{s}$ and rotor slip frequency $\omega_{s l}$ are filtered with first-order transfer functions of $10 \mathrm{~ms}$ time constants. Figure 6 compares the estimated motor speed (grey color) to the actual speed (dark color) acquired from a dc tachometer. These signals are given in electrical values. It is here to note that the 


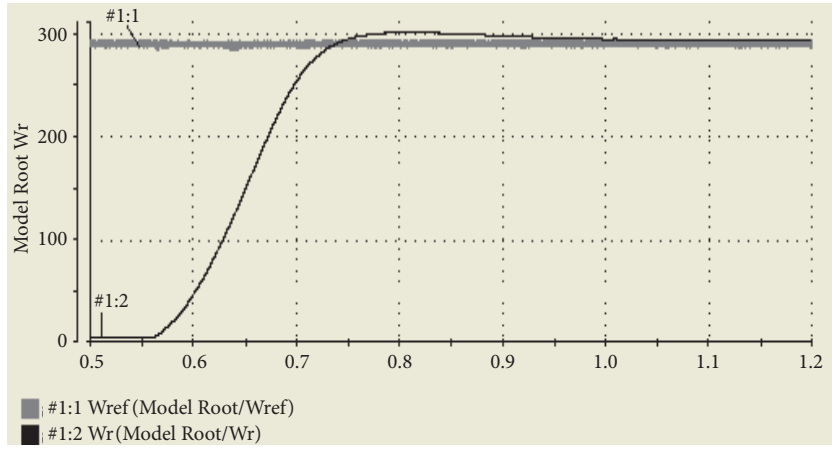

Figure 6: Predicted and actual speed ( $\mathrm{rad} / \mathrm{s})$ versus time (s).

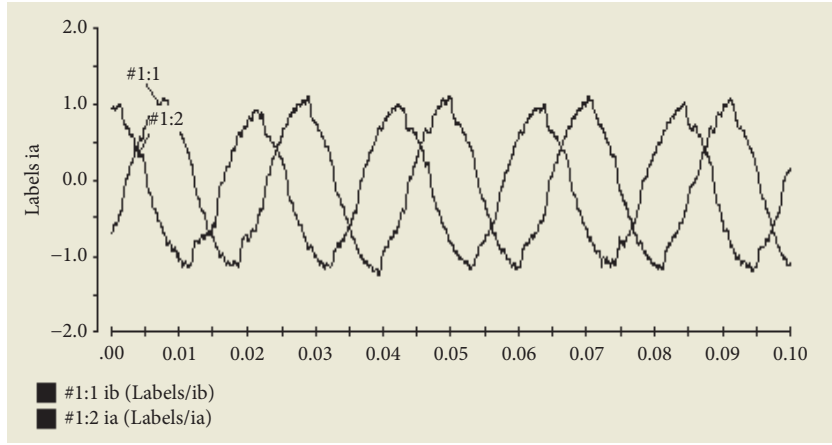

FiguRE 7: Instantaneous waveform of measured stator current.

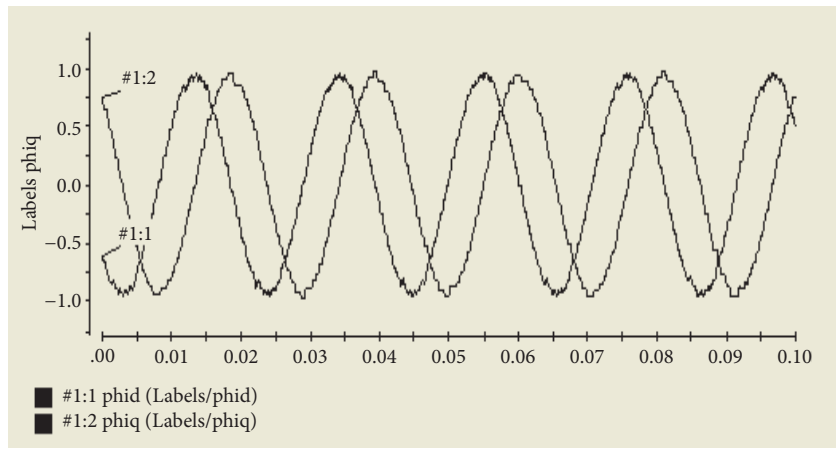

FIGURE 8: Instantaneous waveform of stator flux.

actual speed is only used for the comparison purpose. This figure proves that the control scheme has worked successfully. Estimated speed is very close to the reference value $\omega_{\text {ref }}$. The ripple is not significant. This question will be discussed in Case 3. The overshoot effect on the actual speed is $2.3 \%$ and is rapidly damped.

Figure 7 shows instantaneous waveforms of stator currents $\mathrm{a}$ and $\mathrm{b}$ in steady state. The observed distortion is related to the fact that the motor is not loaded. Figure 8 gives the temporal waveforms of $\mathrm{d}-\mathrm{q}$ components of stator flux vector. This confirms that quality of obtained signals is very similar to that of standard DTC technique.

Case 2 (test under load varying). From the no load steady state operating point previously described, three steps of

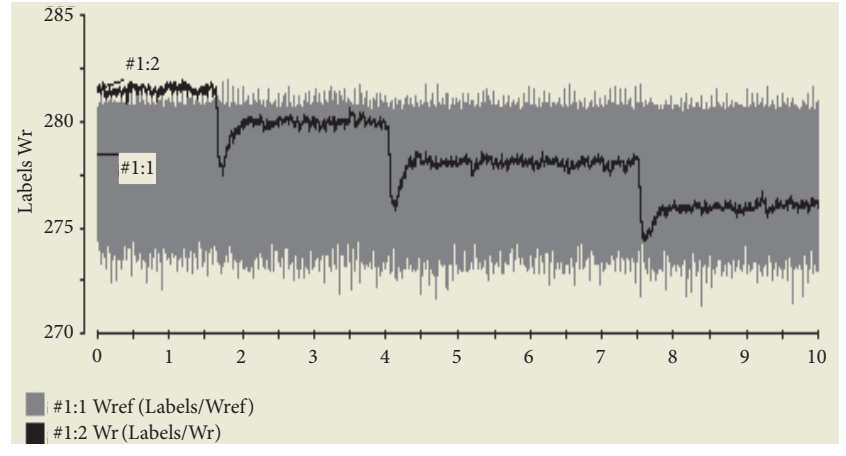

FIGURE 9: Estimated and actual speed during load changing.

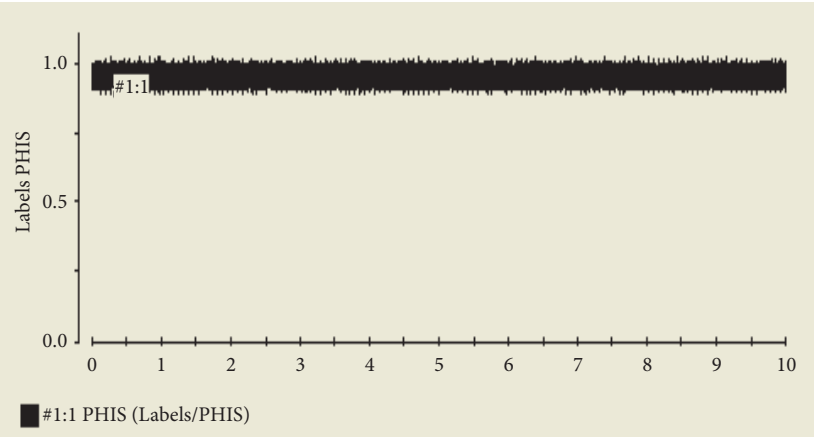

FIGURE 10: Stator flux magnitude during load changing.

motor load are executed by closing the dc generator armature circuit on successive three decreasing resistances. The reference values and hysteresis bands are those of Case 1 . Figure 9 shows that the estimated speed (grey color) has an average value $277 \mathrm{rad} / \mathrm{s}$. The programmed hysteresis band is therefore well respected. Actual motor speed (dark color) has changed from no load condition to full load condition of about $5 \mathrm{rad} / \mathrm{s}$ which corresponds to $1.78 \%$ with respect to initial condition and it also remains in the hysteresis band. Stator flux magnitude is well regulated as shown by Figure 10 . This result implies that speed sensorless objective is well achieved.

Figures 11, 12, and 13 show stator power, electromagnetic torque, and rotor slip frequency behaviors, respectively. The good stability of signal trajectories in fast and important load changing is observed.

Case 3 (speed tolerance enhancement). During simulation and practical tests, it was discovered that the speed hysteresis band could be reduced to a very high precision level. In fact, the proposed control scheme works very well even if one imposes a severe speed hysteresis band around 1 to $2 \%$. This performance cannot be realized in the standard DTC algorithm with this tolerance for the torque. Ripple range of machine electromagnetic torque is very sensitive to the switching period and dc bus voltage of the VSI. A severe torque hysteresis band exhibits a dramatic full down of the DTC algorithm. The same phenomenon occurs if 


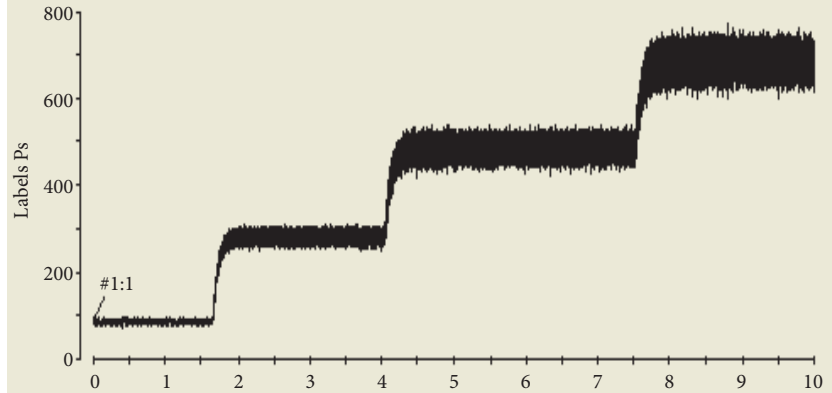

\#1:1 Ps (Labels/Ps)

FIGURE 11: Stator power evolution during load changing.

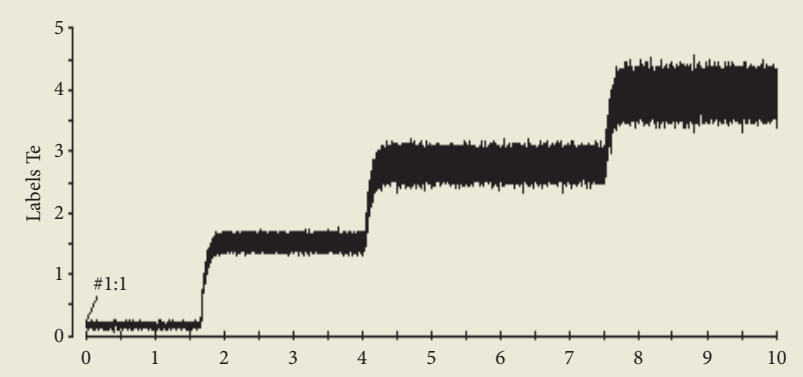

\#1:1 Te (Labels/Te)

FIGURE 12: Torque evolution during load changing.

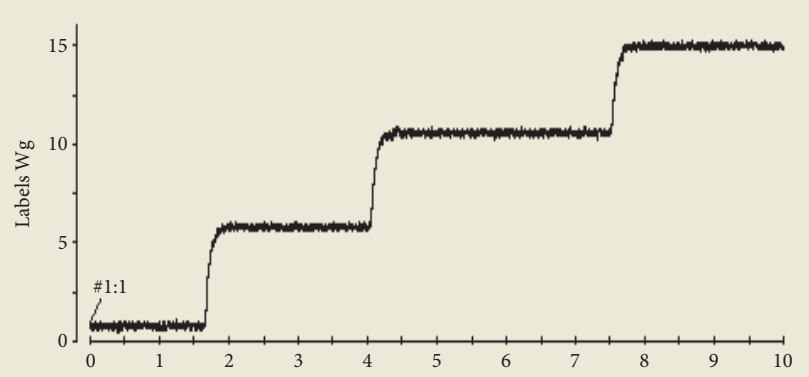

$1: 1 \mathrm{Wg}($ Labels/Wg)

FIGURE 13: Rotor slip pulsation evolution during load changing.

one proceeds to filter the torque signal. For the proposed algorithm, filtering speed estimate is possible.

To illustrate these observations, speed tolerance was reduced to $2 \%(5.86 \mathrm{rad} / \mathrm{sec})$ while keeping other data of Case 1. Figure 14 corresponds to this case and shows estimated motor speed (grey color) and its actual value (dark color). Estimated value remains between 290 and $282 \mathrm{rad} / \mathrm{s}$ which corresponds to an average value closed to $286 \mathrm{rad} / \mathrm{s}$. This means that there is an error of $2.4 \%$ with respect to the reference value $\omega_{\text {ref }}=293 \mathrm{rad} / \mathrm{s}$. When calculating the actual errors corresponding to the difference between actual speed and command speed, an error of $3.1 \%$ was found. Rotor slip pulsation $\omega_{g}$ is shown by Figure 15. Its final value in steady

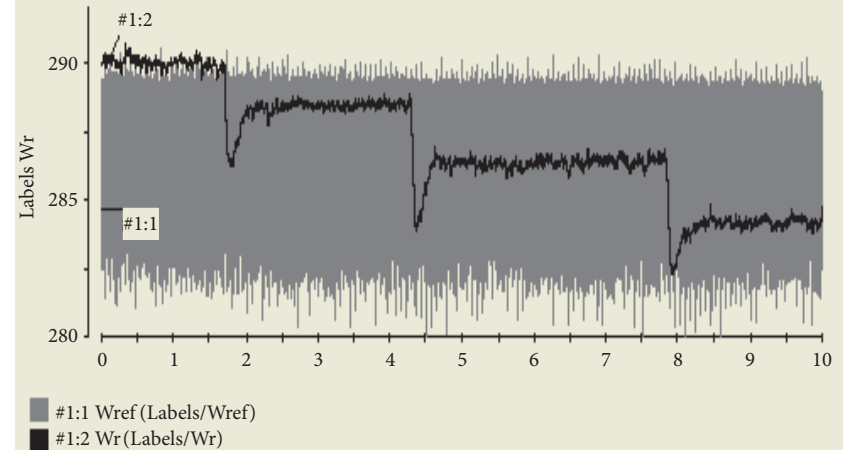

FIGURE 14: Estimated and actual motor speed with 2\% hysteresis band.

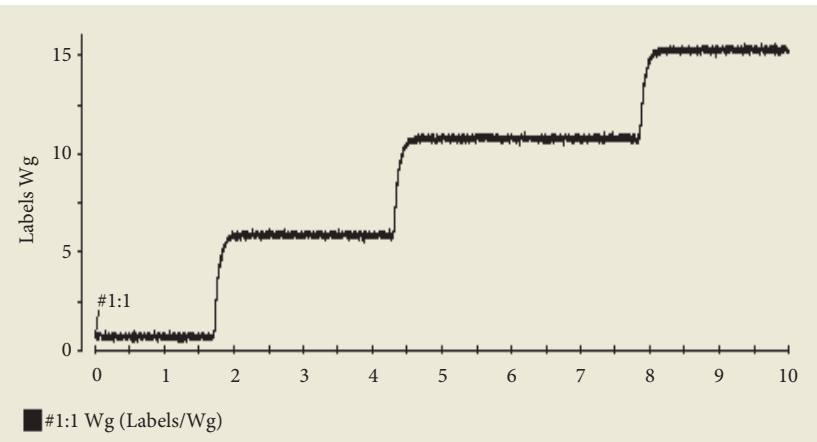

FIGURE 15: Evolution of rotor slip pulsation with $2 \%$ hysteresis band.

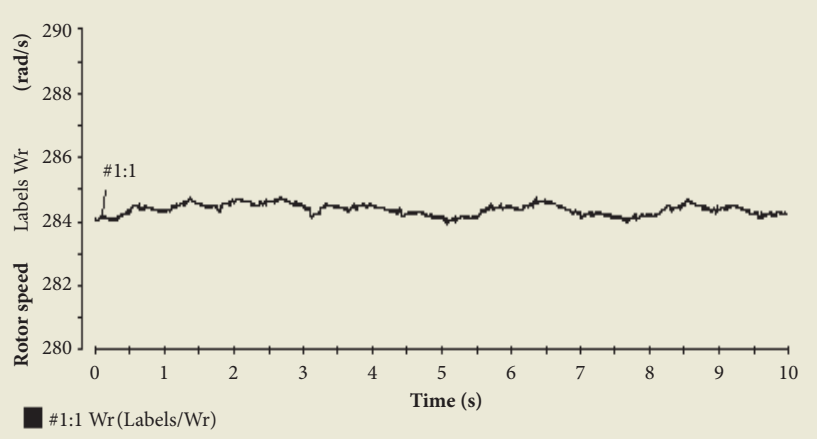

FIGURE 16: Actual electrical machine speed in unregulated scenario.

state with full load is close to $15.5 \mathrm{rad} / \mathrm{s}$. This means that average value of stator pulsation $\omega_{s}$ is $301 \mathrm{rad} / \mathrm{s}$.

To confirm the promising accuracy of developed approach, another program that controls stator flux magnitude and frequency by PI regulators under SPWM modulation technique was used also in real time. Reference values of $\Phi_{s}$ and $\omega_{s}$ are, respectively, set to $1 \mathrm{~Wb}$ and 301 $\mathrm{rad} / \mathrm{s}$. Figure 16 shows that the electrical machine speed is $284 \mathrm{rad} / \mathrm{s}$. That value implies a rotor slip frequency of 17 $\mathrm{rad} / \mathrm{s}$ witch is sufficiently compatible with Figure 13.

Case 4 (direct frequency control). It is obvious that the developed algorithm can be used for direct control of stator 


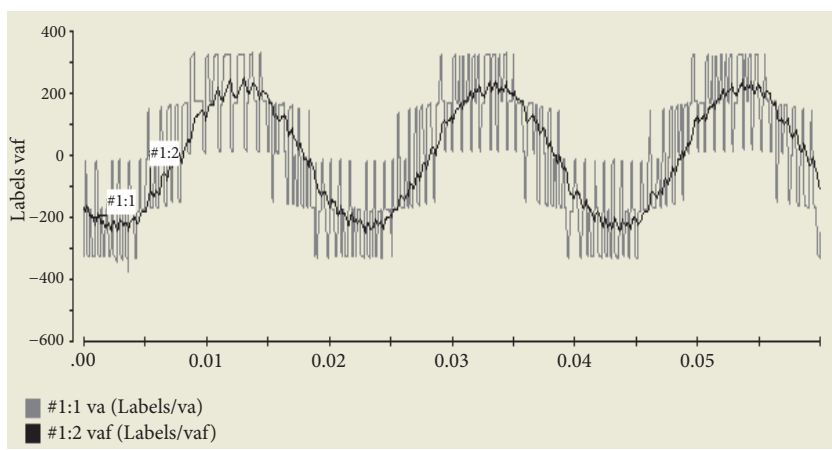

FIGURE 17: Voltage output in DVC case.

electrical frequency. The input $\omega$ of the Takahashi table is simply replaced by $\omega_{s}$. In this case, the algorithm becomes a direct voltage control (DVC) solution. In fact, imposing stator flux magnitude and frequency defines the voltage to supply the motor. This solution was successfully tested and the demanding regime was obtained as shown by Figure 17 corresponding to a demanded frequency of $50 \mathrm{~Hz}$. This figure superposes the switched voltage waveform and the filtered one.

\section{Conclusion}

A direct speed estimation and control scheme has been developed theoretically and practically validated in this work. The proposed approach combines properties of FOC and DTC techniques. It extends DTC structure to speed sensorless direct control. The idea is focused on how to use standard Takahashi switching table to control induction machine speed. Software implementation needs no major modification of the standard DTC scheme. All necessary developments are presented and commented. Real time practical results obtained by the dSpace DS1104 board have good performances. In fact, the error between estimated and measured actual speed does not exceed $2.4 \%$. The proposed technique can provide interesting benefit for industrial applications because it avoids using fragile speed sensors in hostile environment. Furthermore, the method can work as direct voltage control structure by controlling stator electrical frequency.

Admittedly, control without a speed sensor is nowadays a hot topic, especially in terms of the constraints of adaptation of the parameters; adaptation that does not reduce the dynamic stability of the algorithm. This is our perspective subject.

\section{Data Availability}

The data used to support the findings of this study are included within the article.

\section{Conflicts of Interest}

The authors declare that they have no conflicts of interest.

\section{References}

[1] F. Wang, Z. Zhang, X. Mei, J. Rodríguez, and R. Kennel, "Advanced Control Strategies of Induction Machine: Field Oriented Control, Direct Torque Control and Model Predictive Control," Energies, vol. 11, no. 1, p. 120, 2018.

[2] Z. Guo, J. Zhang, Z. Sun, and C. Zheng, "Indirect Field Oriented Control of Three-phase Induction Motor Based on Currentsource Inverter," Procedia Engineering, vol. 174, pp. 588-594, 2017.

[3] H. Krisztián and K. Márton, "Speed Sensorless Field Oriented Control of Induction Machines Using Unscented Kalman Filter," in Proceedings of the IEEE International Conference OPTIM \& Intl ACEMP, pp. 25-27, Brasov, Romania, 2017.

[4] C. Liu and Y. Luo, "Yixiao Luo, Overview of advanced control strategies for electric machines," Chinese Journal of Electrical Engineering, vol. 3, no. 2, pp. 53-61, September 2017.

[5] R. Kaur and G. S. Brar, "Induction motor drives-A literature review," Control Theory and Technology, vol. 9, no. 16, pp. 80718081, 2016.

[6] Y. Wang, N. Niimura, and R. D. Lorenz, "Real-time parameter identification and integration on deadbeat-direct torque and flux control (DB-DTFC) without inducing additional torque ripple," in Proceedings of the 2015 IEEE Energy Conversion Congress and Exposition, pp. 2184-2191, Montreal, QC, Canada, September 2015.

[7] R. Kumar, S. Das, and A. K. Chattopadhyay, "Comparative assessment of two different model reference adaptive system schemes for speed-sensorless control of induction motor drives," IET Electric Power Applications, vol. 10, no. 2, pp. 141154, 2016.

[8] T. Sutikno, N. R. N. Idris, and A. Jidin, "A review of direct torque control of induction motors for sustainable reliability and energy efficient drives," Renewable \& Sustainable Energy Reviews, vol. 32, pp. 548-558, 2014.

[9] H. M. Soliman, "Performance characteristics of induction motor with field oriented control compared to direct torque control," International Journal of Power Electronics and Drive Systems, vol. 7, no. 4, pp. 1125-1133, 2016.

[10] C. Reddy, K. K. Prabhakar, A. K. Singh, and P. Kumar, "Flux estimation in DTC for wide speed range," in Proceedings of the 2016 IEEE Power and Energy Society General Meeting (PESGM), pp. 1-5, Boston, MA, USA, July 2016.

[11] J. W. Finch and D. Giaouris, "Controlled AC electrical drives," IEEE Transactions on Industrial Electronics, vol. 55, no. 2, pp. 481-491, 2008.

[12] D. Casadei, F. Profumo, G. Serra, and A. Tani, "FOC and DTC: two viable schemes for induction motors torque control," IEEE Transactions on Power Electronics, vol. 17, no. 5, pp. 779-787, 2002.

[13] F. Naceri, S. Belkacem, M. Kercha, and T. Benmokrane, "Performance analysis of field-oriented control and direct torque control for sensorless induction motor drives," Asian journal of Information Technology, vol. 6, no. 2, pp. 215-221, 2007.

[14] J. Kim, Y. Lee, J. Lee, and J. Lee, "Improvement of flux estimation using programmable low pass filter with synchronous angular frequency error compensator in sensorless AC induction motor," in Proceedings of the IEEE Transportation Electrification Conference and Expo, Asia-Pacific (ITEC Asia-Pacific '16), pp. 924-928, Busan, South Korea, June 2016.

[15] R. Zhao, Z. Xin, P. C. Loh, and F. Blaabjerg, "A novel flux estimator based on SOGI with FLL for induction machine 
drives," in Proceedings of the IEEE Applied Power Electronics Conference and Exposition (APEC '16), pp. 1995-2002, Long Beach, CA, USA, March 2016.

[16] C. Lascu, I. Boldea, and F. Blaabjerg, "Direct torque control of sensorless induction motor drives: A sliding-mode approach," IEEE Transactions on Industry Applications, vol. 40, no. 2, pp. 582-590, 2004.

[17] I. Boldea, M. C. Paicu, G.-D. Andreescu, and F. Blaabjerg, "“Active Flux" DTFC-SVM sensorless control of IPMSM," IEEE Transactions on Energy Conversion, vol. 24, no. 2, pp. 314-322, 2009.

[18] M. Boussak and K. Jarray, "A high-performance sensorless indirect stator flux orientation control of induction motor drive," IEEE Transactions on Industrial Electronics, vol. 53, no. 1, pp. 41-49, 2006.

[19] R. Zhao, Z. Xin, P. C. Loh, and F. Blaabjerg, "A Novel Flux Estimator Based on Multiple Second-Order Generalized Integrators and Frequency-Locked Loop for Induction Motor Drives," IEEE Transactions on Power Electronics, vol. 32, no. 8, pp. 6286-6296, 2017.

[20] D. Stojić, M. Milinković, S. Veinović, and I. Klasnić, "Improved stator flux estimator for speed sensorless induction motor drives," IEEE Transactions on Power Electronics, vol. 30, no. 4, pp. 2363-2371, 2015.

[21] F. Wang et al., "Predictive Field-Oriented Control for Electric Drives," Chinese Journal of Electrical Engineering, vol. 3, no. 1, pp. 73-78, June 2017.

[22] H. Hiba, H. Ali, and H. Othmen, "DTC-SVM control for three phase induction motors," in Proceedings of the 2013 International Conference On Electrical Engineering and Software Applications (ICEESA), pp. 1-7, Hammamet, Tunisia, March 2013.

[23] Y. Oguz and M. Dede, "Speed estimation of vector controlled squirrel cage asynchronous motor with artificial neural networks," Energy Conversion and Management, vol. 52, no. 1, pp. 675-686, 2011.

[24] F. Zidani and D. Diallo, "Direct torque control of induction motor with fuzzy stator resistance adaptation," IEEE Transactions on Energy Conversion, vol. 21, no. 2, pp. 619-621, 2006.

[25] Y. Liu, Z. Q. Zhu, and D. Howe, "Instantaneous torque estimation in sensorless direct-torque-controlled brushless DC motors," IEEE Transactions on Industry Applications, vol. 42, no. 5, pp. 1275-1283, 2006.

[26] O. Ellabban, J. Van Mierlo, and P. Lataire, "A comparative study of different control techniques for an induction motor fed by a Z-source inverter for electric vehicles," in Proceedings of the 3rd IEEE International Conference on Power Engineering, Energy and Electrical Drives, Torremolinos, Spain, May 2011.

[27] G. Foo, S. Sayeef, and M. F. Rahman, "Low-speed and standstill operation of a sensorless direct torque and flux controlled IPM synchronous motor drive," IEEE Transactions on Energy Conversion, vol. 25, no. 1, pp. 25-33, 2010. 


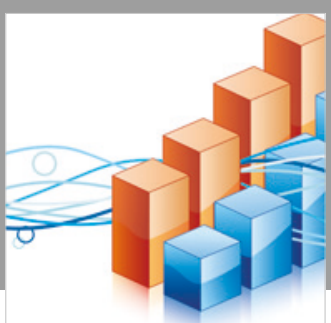

Advances in

Operations Research

\section{-n-m}
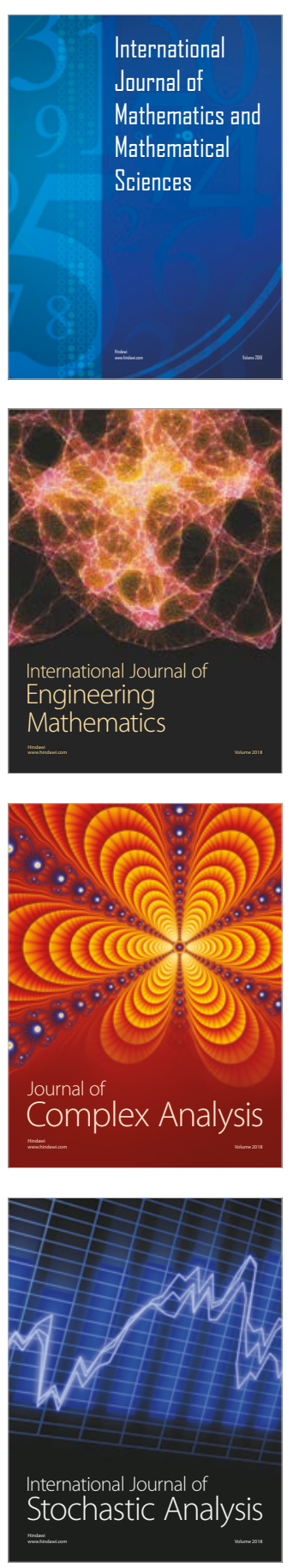
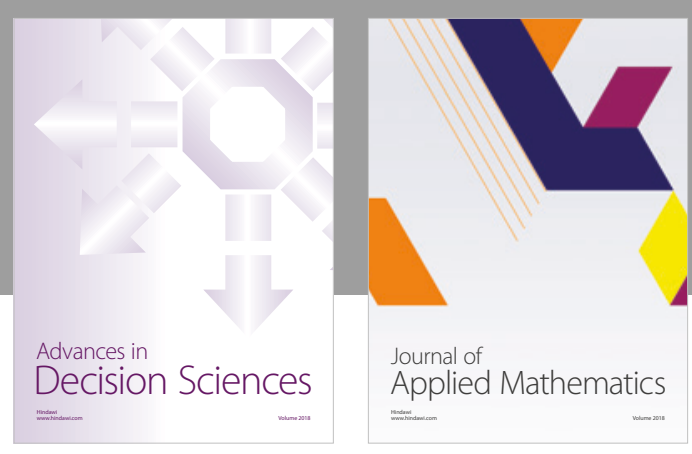

Journal of

Applied Mathematics
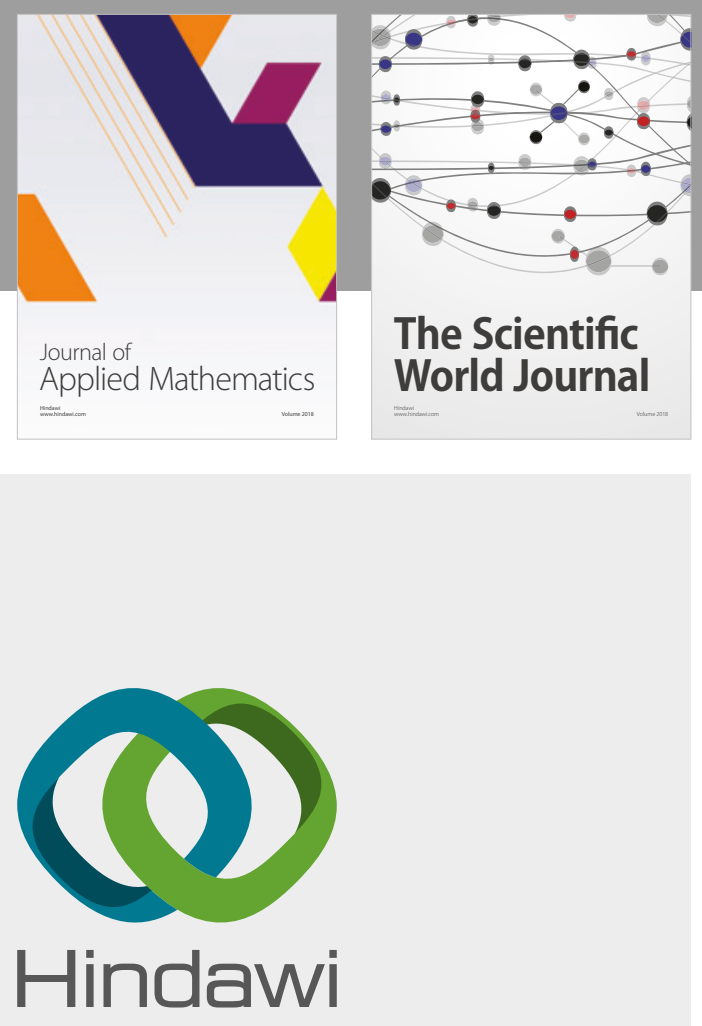

Submit your manuscripts at

www.hindawi.com

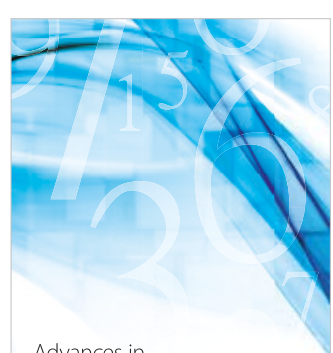

Advances in
Numerical Analysis
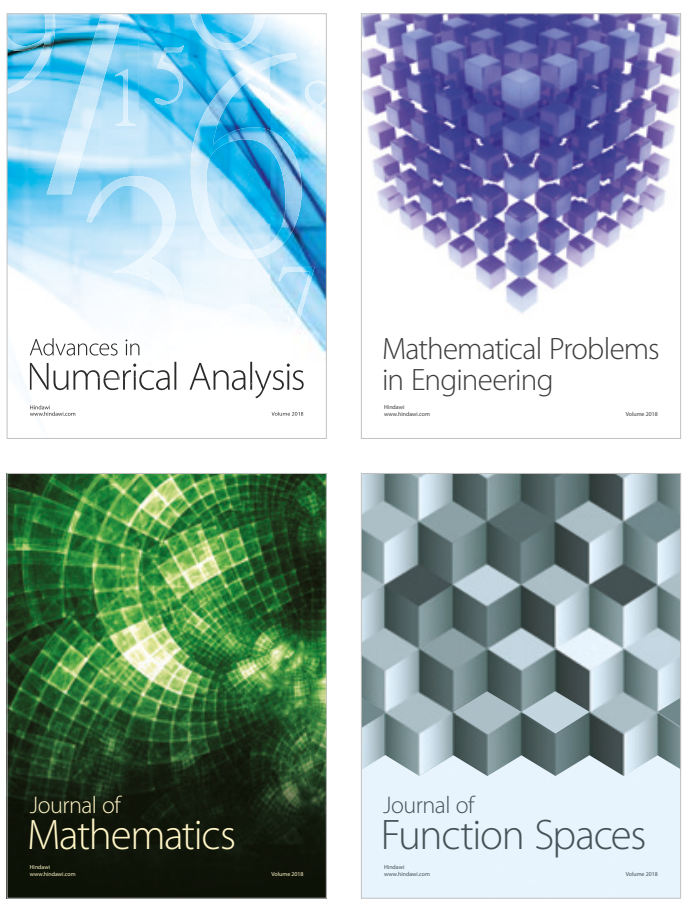

Mathematical Problems in Engineering

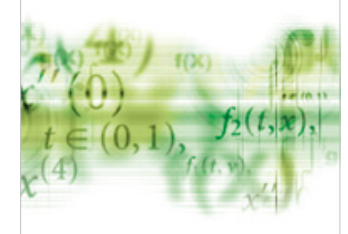

International Journal of

Differential Equations

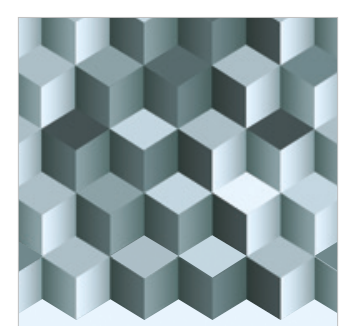

Journal of

Function Spaces

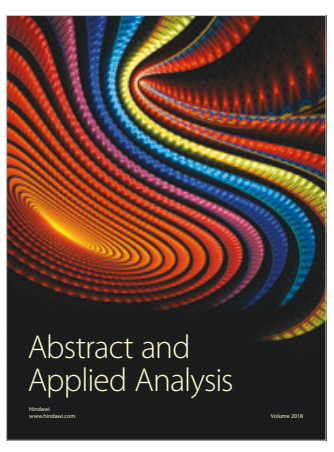

The Scientific

World Journal

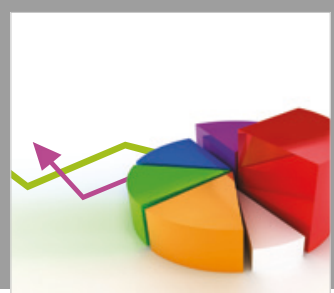

Journal of

Probability and Statistics
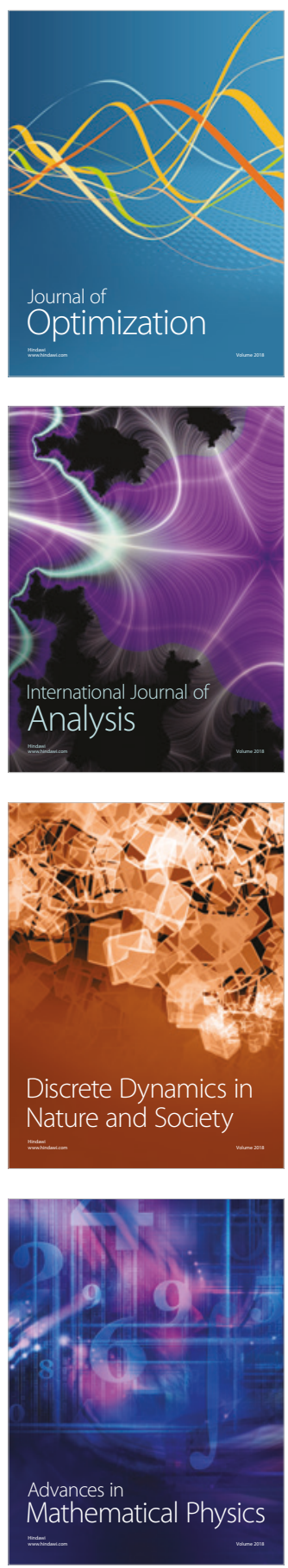